\title{
Pemanfaatan Teknologi QR Code Untuk Verifikasi Akta Notaris (PPAT)
}

\author{
Asep Id Hadiana ${ }^{1}$ \\ ${ }^{1}$ Jurusan Teknik Informatika, FMIPA UNJANI \\ Email: ahadiana@gmail.com
}

\begin{abstract}
ABSTRAK
Akta Notaris dan Pejabat Pembuat Akta Tanah (PPAT) merupakan sebuah dokumen yang sangat penting. Hal ini dikarenakan dokumen atau akta yang dibuat oleh Notaris/PPAT merupakan dokumen yang memiliki kekuatan hukum yang dijamin dengan undang-undang. Pada kenyataannya, terdapat beberapa kasus dimana akta Notaris/PPAT dipalsukan oleh beberapa pihak yang tidak bertanggung jawab. Oleh karena itu diperlukan sebuah cara untuk melakukan verifikasi atas keaslian akta Notaris/PPAT tersebut. QR Code merupakan barcode dua dimensi yang disusun secara matriks. Dengan konsep ini, data dan informasi dapat disimpan lebih banyak di dalam sebuah $Q R$ Code dibandingkan dengan barcode satu dimensi yang hanya dapat menyimpan data dalam satu baris saja. QR code sebagai sebuah teknologi yang relatif baru, dapat digunakan untuk penanda pada akta yang dibuat oleh Notaris/PPAT, sehingga pemalsuan akta notaris/PPAT dapat diminimalisir.
\end{abstract}

Kata kunci: akta, notaris, ppat, pemalsuan, verifikasi

\begin{abstract}
Notary Deed and the Land Deed Official ( PPAT ) is a very important document. his is because the document or deed of Notary / PPAT is a document that has the force of law guaranteed by law. In fact, there are some cases where the deed of Notary / PPAT falsified by some irresponsible parties. Therefore we need a way to verify the authenticity of the deed of Notary / PPAT. QR Code is a two-dimensional barcode is arranged in a matrix. With this concept, data and more information can be stored in a QR Code compared to the one-dimensional barcode that can only store data in a single line. $Q R$ code as a relatively new technology, can be used for a marker on the deed of Notary I PPAT, making counterfeiting notarial deed / PPAT can be minimized .
\end{abstract}

Keywords: deed, notary, ppat, verivication. 


\section{LATAR BELAKANG}

Akta Notaris dan Pejabat Pembuat Akta Tanah (PPAT) merupakan sebuah dokumen yang sangat penting. Hal ini dikarenakan dokumen atau akta yang dibuat oleh Notaris/PPAT merupakan dokumen yang memiliki kekuatan hukum yang dijamin dengan undang-undang. Pada kenyataannya, terdapat beberapa kasus dimana akta Notaris/PPAT dipalsukan oleh beberapa pihak yang tidak bertanggung jawab. Pemalsuan tersebut diatas menyebabkan banyak kasus yang berujung kepada pengadilan. Oleh karena itu diperlukan sebuah cara untuk melakukan verifikasi atas keaslian akta Notaris/PPAT tersebut

QR CODE merupakan teknologi yang relatif baru. Sebagai teknologi yang relatif baru, penggunaan QR Code masih sangat terbatas, khususnya di Indonesia. Bila dilihat dari sisi teknologi, QR Code memiliki kemiripan dengan Barcode, bahkan dapat dikatakan bahwa QR Code merupakan perbaikan dari barcode yang sudah sangat familiar dalam kehidupan kita. Salah satu keunggulan QR Code dibandingkan dangan barcode adalah bahwa QR Code mampu menampung data lebih banyak daripada barcode. Keunggulan ini tentu bila dimanfaatkan dengan baik akan berdampak positif bagi penggunanya.

Beberapa faktor yang mendukung penerapan QR Code diantaranya adalah :

1. Penggunaan Smartphone yang semakin meluas

2. QR Code bersifat FREE.

3. Semakin banyak orang yang mengakses internet melalui Mobile Devices.

4. Pembuatan kode untuk QR Code sangat mudah, dan dapat menggunakan berbagai aplikasi yang bersifat free.

QR Code Scanner dapat menggunakan Smartphone. Banyak aplikasi QR Cide scanner yang tersedia secara gratis, misalnya yang berbasis android, symbian, ios.

\section{METODOLOGI PENELITIAN}

Barcode merupakan sebuah simbol penandaan objek nyata yang terbuat dari pola batang-batang berwarna hitam dan putih ${ }^{[1]}$. Seiring dengan perkembangan ilmu pengetahuan dan teknologi maka teknik penandaan objek dunia nyata agar mudah dikenali semakin berkembang, berawal dari ditemukannya barcode linear, kemudian barcode 2D, hingga teknik penandaan menggunakan infra merah (IR) ${ }^{[2]}$ dan teknik penandaan menggunakan frekwensi radio (RFID) ${ }^{[3]}$.

QR Code adalah suatu jenis kode matriks atau barcode dua dimensi yang dikembangkan oleh Denso Wave, sebuah divisi Denso Corporation yang merupakan sebuah perusahaan Jepang dan dipublikasikan pada tahun 1994 dengan fungsionalitas utama yaitu dapat dengan mudah dibaca oleh pemindai QR merupakan singkatan dari quick response atau respons cepat, yang sesuai dengan tujuannya adalah untuk menyampaikan informasi dengan cepat dan mendapatkan respons yang cepat pula. Berbeda dengan barcode, yang hanya menyimpan informasi secara horizontal, QR Code mampu menyimpan informasi secara horizontal dan vertikal, oleh karena itu secara otomatis QR Code dapat menampung informasi yang lebih banyak daripada barcode.

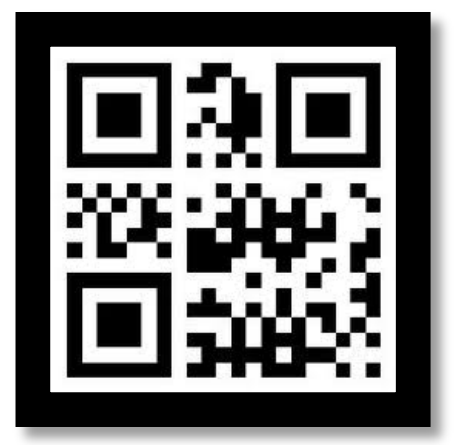

Gambar 1. QR Code 


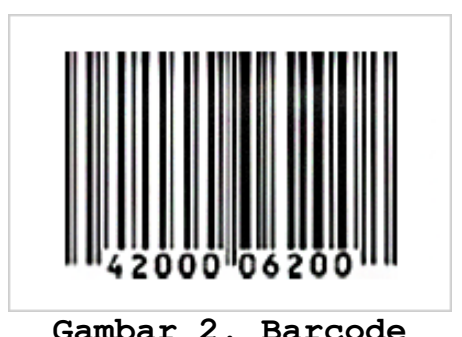

QR Code memiliki kapasitas tinggi dalam data pengkodean, yaitu mampu menyimpan semua jenis data, seperti data numerik, data alphabetis, kanji,kana,hiragana,simbol,dan kode biner. Secara spesifik, QR Code mampu menyimpan data jenis numerik sampai dengan 7.089 karakter, data alphanumerik sampai dengan 4.296 karakter, kode binari sampai dengan 2.844 byte, dan huruf kanji sampai dengan 1.817 karakter.

Selain itu QR Code memiliki tampilan yang lebih kecil daripada barcode. Hal ini dikarenakan QR Code mampu menampung data secara horizontal dan vertikal, oleh karena itu secara otomatis ukuran dari tampilannya gambar QR Code dapat hanya seperspuluh dari ukuran sebuah barcode. Tidak hanya itu QR Code juga tahan terhadap kerusakan, sebab QR Code mampu memperbaiki kesalahan sampai dengan 30\%. Oleh karena itu, walaupun sebagian simbol QR Code kotor ataupun rusak, data tetap dapat disimpan dan dibaca. Tiga tanda berbentuk persegi di tiga sudut memiliki fungsi agar simbol dapat dibaca dengan hasil yang sama dari sudut manapun sepanjang 360 derajat

Saat ini penggunaan QR Code sudah cukup luas. Banyak negara di dunia, terutama Jepang, telah menerapkan teknologi QR Code pada perindustriannya. Sementara di Indonesia, QR Code sudah diterapkan pada beberapa perusahaan. Salah satunya adalah pada surat kabar Kompas, yang mengklaim sebagai pelopor penggunaan QR Code di Indonesia, yang diterbitkan oleh Kelompok Kompas Gramedia [4]. Hal ini terlihat pada suratkabar tersebut dimana terdapat QR Code yang merepresentasikan artikel pada surat kabar tersebut.

Untuk membaca QR Code diperlukan aplikasi QR Code Reader yang mudah untuk kita dapatkan, baik itu yang gratis ataupun yang berbayar.

Sedangkan untuk membuat QR Code nya itu sendiri, kita juga dapat memanfaatkan aplikasi atau beberapa situs di internet yang menyediakan aplikasi untuk membuat QR Code.

Dalam penelitiannya, M.Pasca Nugraha dan Rinaldi Munir, menjelaskan bahwa Prosedur pembangkitan QR Code dari sebuah teks dapat dijelaskan dengan diagram alir pada gambar 3. [5] 
ISSN : 2528-0015

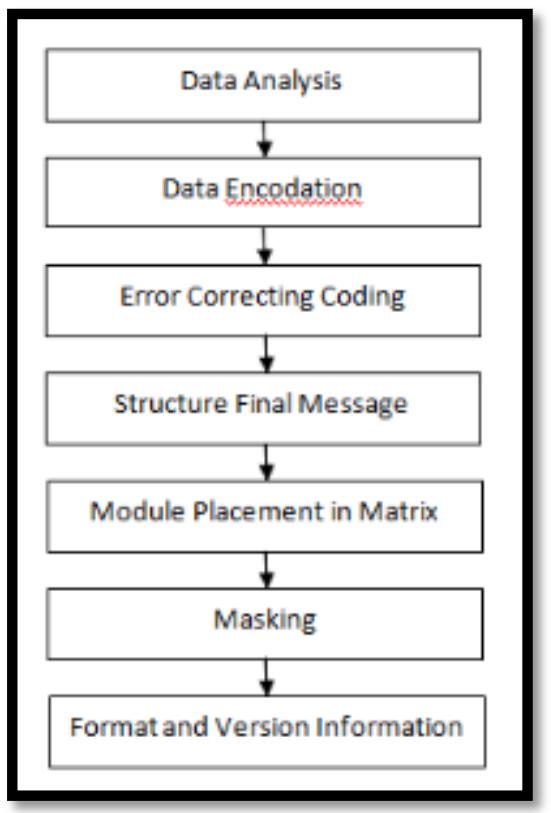

Gambar 3. Diagram Alir Proses pembangkitan QR Code

Dan dalam penelitian yang sama [5], M.Pasca Nugraha dan Rinaldi Munir, menjelaskan bahwa Prosedur pembacaan QR Code dapat dijelaskan dengan diagram alir pada gambar 4.

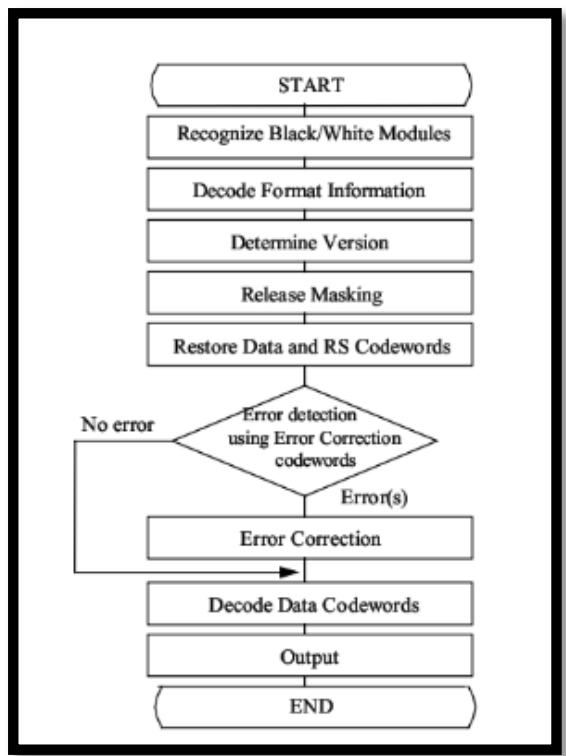

Gambar 4. Diagram Alir Proses Pembacaan QR Code.

\section{ANALISIS DAN PEMBAHASAN}

\subsection{Perancangan format link QR Code}

Format link untuk QR Code :

http://xxxabc.com/akta/?no_akta=[noakta_tahun]

contoh : http://xxxabc.com/akta/?no akta=01 2015

(xxxabc.com adalah contoh nama situs notaris yang bersangkutan). 
Dari format link diatas dapat dijelaskan bahwa nomor akta terdiri dari nomor aktanya itu sendiri dan tahun akta, dimana no akta dan tahun akta dipisahkan oleh tanda " ".

\subsection{Pembuatan QR Code}

Pembuatan QR Code dapat memanfaatkan situs internet yang ada, misalnya http://www.qrstuff.com.

Pada situs tersebut, kita tinggal memasukkan data yang ingin dibuatkan QR Codenya, dalam hal ini adalah link dokumen akta.

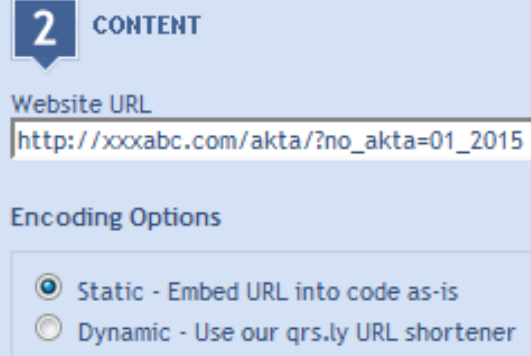

Gambar 5. Pembuatan QR Code pada qrstuff.com

Setelah memasukkan link akta pada qrstuff.com, maka akan digenerate secara otomatis QR Codenya, seperti dapat dilihat pada gambar 5.

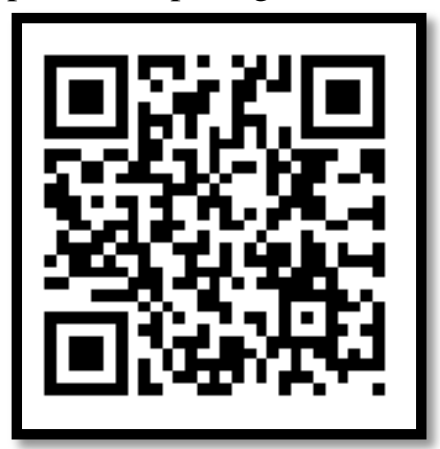

Gambar 6. QR Code hasil generate

Langkah selanjutnya adalah tinggal mendownload file QR Code dan disisipkan pada dokumen akta notaris/PPAT. 
ISSN : 2528-0015

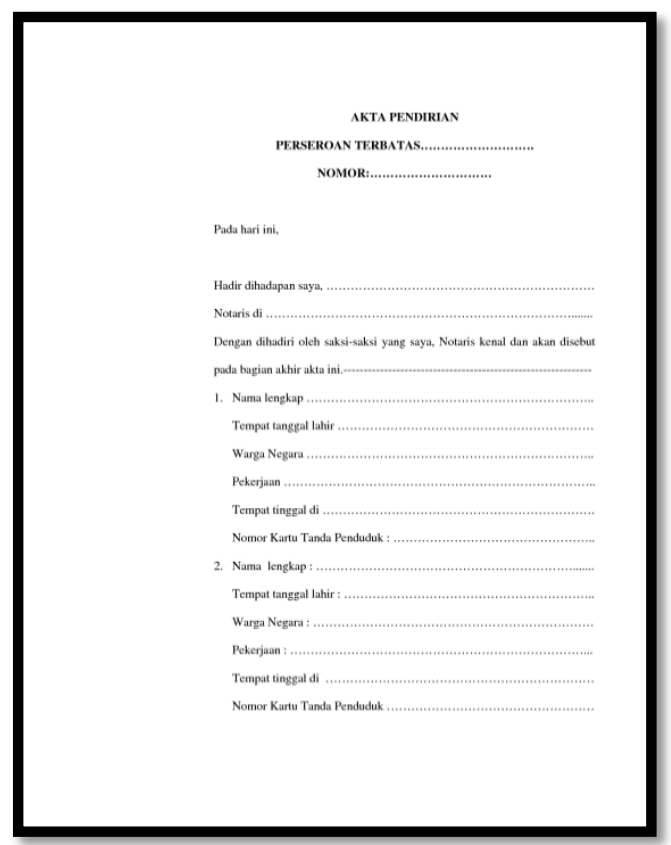

Gambar 7 Contoh Akta Notaris sebelum diberikan QR Code

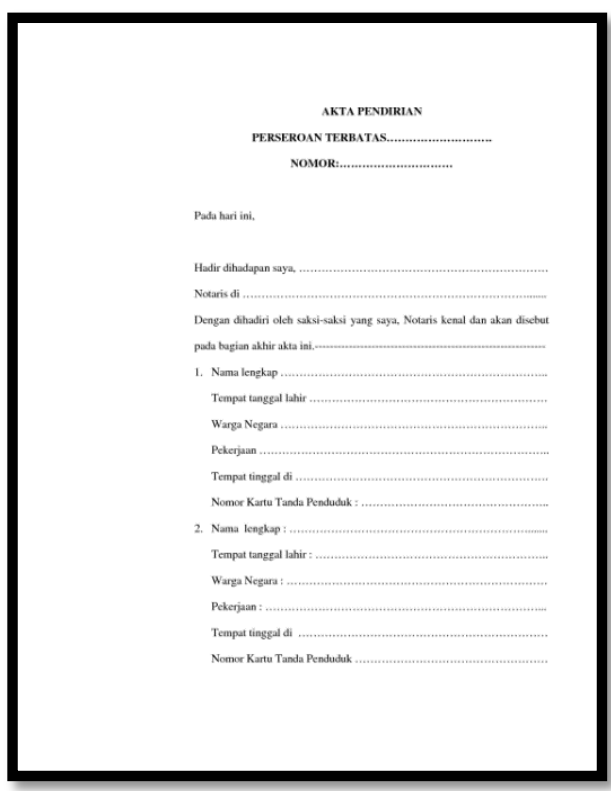

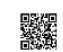

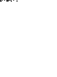




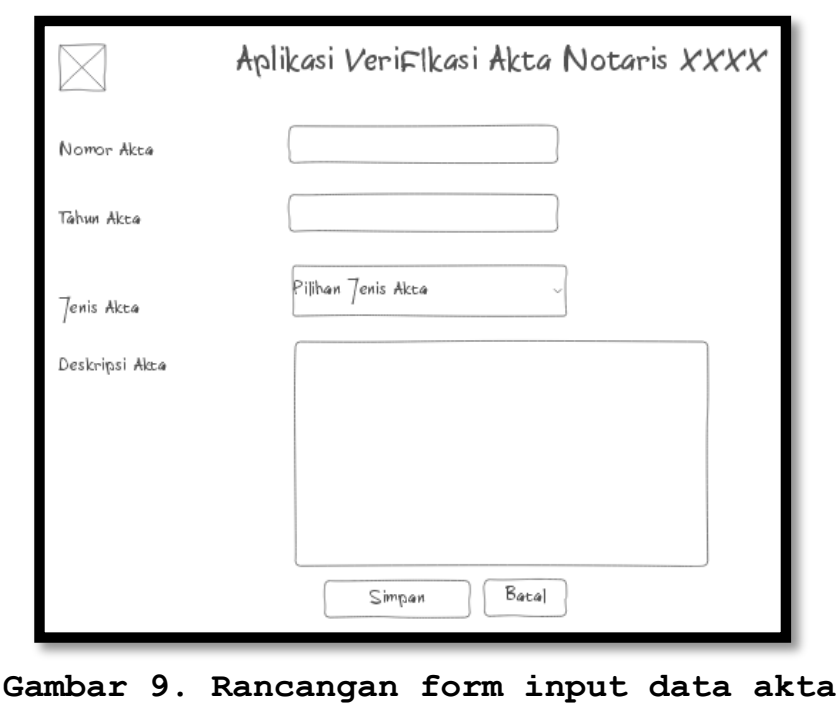

Gambar 7 merupakan bagian dari back end aplikasi verifikasi akta Notaris/ PPAT. Dimana pihak Notaris/PPAT memasukkan data kedalam aplikasi tersebut.

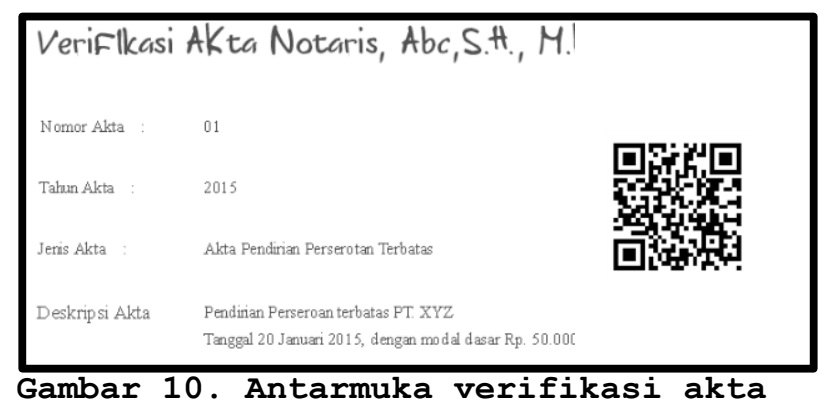

Gambar 10. Merupakan tampilan antarmuka ketika QR Code pada akta di tag dengan menggunakan aplikasi QR Code reader oleh pengguna. Dengan pembacaan QR Code pada dokumen dengan menggunakan QR Code Reader, akan dilihat kecocokan antara data pada dokumen dengan data asli yang ada pada aplikasi di bagian back end.

Dengan adanya verifikasi ini, maka kasus akta palsu akan dapat diminimalisir, karena pengguna dapat langsung mengecek kebenaran dari akta yang mereka punya, cukup hanya dengan melakukan pembacaan QR Code pada akta, dengan menggunakan aplikasi QR Code reader yang terinstall pada smartphone mereka.

\section{KESIMPULAN}

Dari penelitian ini dapat disimpulkan bahwa QR Code dapat dijadikan sebagai alat bantu bagi Notaris/PPAT dan juga bagi masyarakat umum, khususnya pemilik Akta Notaris/PPAT untuk melakukan verifikasi atas keaslian akta yang mereke miliki. Sehingga kasus Pemalsuan Akta Notaris/ PPAT akan dapat diminimalisir. Penelitian ini masih jauh dari sempurna, banyak hal yang belum tercakup dalam penelitian ini, seperti proses pembacaan dan pembuatan QR Code masih menggunakan aplikasi pihak ketiga. Kedepannya diharapkan dapat menggunakan Aplikasi pembuat dan pembaca QR Code sendiri. 


\section{DAFTAR RUJUKAN}

[1] http://www.denso-wave.com/qrcode/aboutqr- e.html (diakses 3 April 2009)

[2] Swetake .Y,1997-2009, How to create QRcode,Jepang:

http://www.swetake.com/qr/qr1_en.htm

[3] Wellner, Pierre D.1993. Adaptive Thresholding for the Digital Desk, Cambridge: Rank Xerox Research Centre Cambridge Laboratory.

[4] Mihardja, Taufik. 2009 QR Code Kompas Perkaya Konten bagi Pembaca. Diakses pada Desember 2010 di

http://tekno.kompas.com/read/2009/06/15/0850503/QRCode.Kompas.Perkaya.Konten.bagi.Pem baca

[5] Nugraha, Pasca \& Munir, Rinaldi, 2011, Pengembangan Aplikasi QR Code Generator dan QR Code Reader dari Data Berbentuk Image, Konferensi Nasional Informatika. 